\title{
Integration Of Pipe Models In Delphin And NANDRAD
}

\author{
Dirk Weiß ${ }^{1}$, Katja Tribulowski ${ }^{1}$, Stephan Hirth $^{1}$, and Heiko Fechner ${ }^{1}$
}

${ }^{1}$ TU Dresden, Faculty Of Architecture, Institute For Building Climatology, Germany

\begin{abstract}
The component simulation program DELPHIN, which is usually used for component simulation including coupled heat and moisture transport, has also implemented a pipe model that is currently not documented. This model can be used for various purposes, including the modelling of heat input/output by surface heating/cooling systems in building structures. Furthermore, it allows an estimation of energy gains and storage potentials by ground collectors by considering the ground including the collector pipe, etc. The same pipe model is implemented isotropically in NANDRAD in order to model and to consider underfloor heating systems in the thermal building simulation. The implementation of this pipe model for DELPHIN (component simulation program) and NANDRAD (building simulation program) is described, investigated and documented in this paper for underfloor heating and cooling systems. Especially the heat transfer between pipe wall and fluid is discussed in more detail. Therefore, the parameterization and the flaw between the anisotropic tube model (two-dimensional heat radiation inside the component) in Delphin and the isotropic model (heat input to a component layer) in NANDRAD are being examined.
\end{abstract}

\section{Introduction}

Low-temperature surface heating/cooling systems are nowadays standard in the design and the energy evaluation of buildings. A test of these systems is performed for the building simulation solver NANDRAD. Here, a $1 \mathrm{D}$ calculation performed by NANDRAD is compared to a 2D calculation performed by Delphin. The examined construction in this case is an underfloor heating model consisting of a plastic pipe inside the screed.

\section{Software Description}

\subsection{DELPHIN}

DELPHIN is a simulation software for coupled heat, moisture and mass transport in capillary-porous building materials. One-, two- and rotationally symmetrical threedimensional (DELPHIN 5) or fully three-dimensional calculations (DELPHIN 6) are possible. Delphin is already used by numerous engineering offices and universities for research as well as economic projects.[2]

\subsection{NANDRAD}

NANDRAD is a modern building simulation platform for the dynamic evaluation of the energy efficiency of buildings. It has been particularly developed to efficiently calculate complex and large buildings. At the same time, the integrated physical models are showing a high level of detail. The sophisticated feature of NANDRAD is that it meets two essential requirements of modern building simulation.[5] On the one hand, the building is not only considered passively, but can also produce and store energy (e.g. Prosumer and Consumer). On the other hand, NANDRAD enables holistic energy simulations, i.e. the interaction of building storage masses, peak loads and energy demand in the building, as well as the associated system and control technology, is supported.[7]

\section{Validation Cases}

A variant matrix is set up for the preparation of the comparative cases. This contains 5 different variations:

- Installation distance

- Internal pipe diameter

- Inlet temperature

- Boundary condition (Ground, Storey)

- Mass flux

The first installation situation describes the installation of an underfloor heating system as a ceiling between two rooms. The second installation situation describes a room with underfloor heating integrated in a foundation slab that is in contact with the ground.

The following constant assumptions apply:

- The room air temperature in the upper one is kept at a constant $20^{\circ} \mathrm{C}$. The fluid supplies the necessary heat flows.

- Installation situation ceiling $\rightarrow$ Room air temperature in the lower room is also kept at a constant of $20^{\circ} \mathrm{C}$.

- Installation situation foundation slab $\rightarrow$ Ground temperature is kept at a constant of $12^{\circ} \mathrm{C}$ on the contact surface.

- For each component the heat convection coefficients from the air to the surface are $10 \mathrm{~W} / \mathrm{m}^{2} \mathrm{~K}$ at the top and if available at the bottom.

- The construction is as shown in figure 2 for both boundary variants. Overheating of a space does not occur. 
- The mass flux is constantly calculated considering the fluid velocity and the inside diameter of the pipe.

- The pipe material is given a thermal conductivity of $0.4 \mathrm{~W} / \mathrm{mK}$ and a wall thickness of $2 \mathrm{~mm}$.

Variable assumptions:

- The fluid inlet temperature varies between $25^{\circ} \mathrm{C}$, $30^{\circ} \mathrm{C}$ and $35^{\circ} \mathrm{C}$.

- The installation distance varies between $50 \mathrm{~mm}$, $100 \mathrm{~mm}$ and $200 \mathrm{~mm}$ (figure 1).

- $\quad$ There are 4 different variants of the internal pipe diameter: $8 \mathrm{~mm}, 10 \mathrm{~mm}, 12 \mathrm{~mm}$ and $16 \mathrm{~mm}$.

- $\quad$ For the installation condition "ground", the thickness of the insulation in the construction is tripled and a ground contact is implemented. See figure 2 and table 1.

- $\quad$ For the case "boundary condition storey" the mass fluxes are varied by applying fluid velocities of $0.1 \mathrm{~m} / \mathrm{s}$ and $1 \mathrm{~m} / \mathrm{s}$.

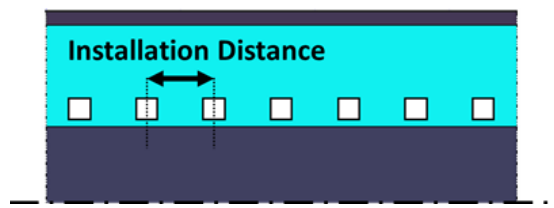

Fig. 1. Installation distance

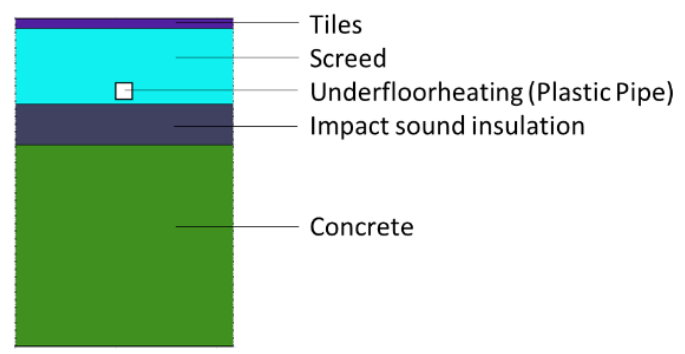

Fig. 2. Component structure

The first installation situation describes the installation of an underfloor heating system as a ceiling between two rooms. The second installation situation describes a room with underfloor heating integrated in a foundation slab that is in contact with the ground.

Table 1. Material details

\begin{tabular}{|l|c|c|c|c|}
\hline & $\begin{array}{c}\mathbf{d} \\
{[\mathrm{mm}]}\end{array}$ & $\begin{array}{c}\boldsymbol{\lambda} \\
{[\mathbf{W} / \mathbf{m K}]}\end{array}$ & $\begin{array}{c}\mathbf{P} \\
{\left[\mathbf{k g} / \mathbf{m}^{\mathbf{3}}\right]}\end{array}$ & $\begin{array}{c}\mathbf{C}_{\mathbf{e}} \\
{[\mathrm{J} / \mathrm{KgK}]}\end{array}$ \\
\hline Tiles & 10 & 1.00 & 2000 & 900 \\
\hline Screed & 54 & 0.94 & 2058 & 689 \\
\hline Screed & 16 & 0.94 & 2058 & 689 \\
\hline Screed & 5 & 0.94 & 2058 & 689 \\
\hline Insulation & $40 \mid 120$ & 0.03 & 40 & 1500 \\
\hline Concrete & 200 & 2.10 & 2320 & 850 \\
\hline
\end{tabular}

By varying the mass fluxes with the selected fluid velocities, different flow conditions result. Therefore, the heat transfer coefficients as well as the mass fluxes must be recalculated. For both variants they are listed in Table 2 .

Table 2. Input data variation mass flux

\begin{tabular}{|c|c|c|c|}
\hline & pipe diameter $d$ & $\begin{array}{c}\text { (laminar) } \\
\mathrm{v}=0.1 \mathrm{~m} / \mathrm{s}\end{array}$ & $\begin{array}{c}\text { (turbulent) } \\
\mathrm{v}=1 \mathrm{~m} / \mathrm{s}\end{array}$ \\
\hline \multirow{4}{*}{ hc Fluid [W/m² $\mathrm{K}]$} & 8 & 275 & 1390 \\
\hline & 10 & 220 & 1800 \\
\hline & 12 & 183 & 2210 \\
\hline & 16 & 137 & 3010 \\
\hline \multirow{4}{*}{ Mass flux $[\mathrm{kg} / \mathrm{s}]$} & 8 & 0.005 & 0.025 \\
\hline & 10 & 0.0078 & 0.039 \\
\hline & 12 & 0.011 & 0.056 \\
\hline & 16 & 0.02 & 0.1 \\
\hline
\end{tabular}

The temperatures and heat fluxes from the floor into the upper room are of interest. In addition to the surface temperatures, the heat fluxes from the floor into the lower and upper room as well as the heat fluxes from the fluid and the fluids outlet temperatures are considered and evaluated.

\section{1D-Modeling}

\subsection{NANDRAD}

Two basic project files are created in NANDRAD. The first one represents the boundary situation "storey", the second one represents the installation situation "ground". For "storey", two rooms are modelled. The room temperatures are set to a constant of $20^{\circ} \mathrm{C}$. The heat convection coefficients are defined as $10 \mathrm{~W} / \mathrm{m}^{2} \mathrm{~K}$ for the top surface as well as for the bottom surface of the ceiling.

In the calculation algorithm of NANDRAD, the pipe model is coupled with the component layer via the temperature and the heat flux. The heat input from the pipe is assigned to a layer in the NANDRAD project file. The interaction between component layer temperatures and fluid temperature takes place at each time step and therefore their calculation is coupled. The definition of the underfloor heating model in the NANDRAD project file is shown in the following figure:

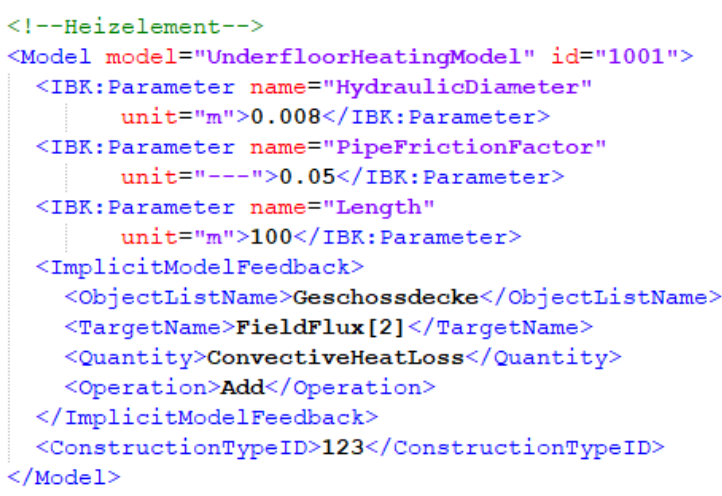

Fig. 3. NANDRAD code excerpt 


\subsection{DELPHIN}

In the $1 \mathrm{D}$ case the data description is similar to NANDRAD. The only difference is that the heat flux is assigned to the respective layer by a controllable schedule. Therefore, pipe parameters and fluid properties are not required. For the heat flux a constant schedule with the value of $132.6 \mathrm{~W}$ is predefined.

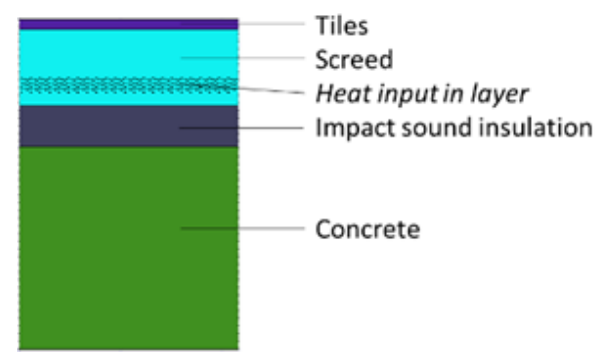

Fig. 4. Position of heat input

\section{2D-Modeling}

\subsection{Delphin}

The integration of a pipe model is possible in 2D design. Only rectangular geometries can be implemented in Delphin. Therefore, the tube can either be stepped or completely described as a rectangle. In the present case the rectangular geometry is selected for the tube. As boundary condition for the rectangular element, the pipe model is assigned. As a result, each adjacent element at the respective edge interacts with the temperatures and heat fluxes of the pipe model.

To simplify the model, symmetry axes of the construction are used. For a better illustration, an axis of symmetry, where the entire pipe is shown, was chosen. Then the outputs were defined for the relevant elements. On the one hand these are element and average surface temperatures and the heat fluxes over component edges and through the pipe wall. Furthermore, the inlet and outlet temperatures were set as output.

\section{Extended considerations:}

In order to realistically model an underfloor heating system, the room geometry of the pipe installation must be considered. Underfloor heating pipes are usually installed in a way that a pipe from the inlet is next to a pipe from the outlet. This is usually implemented in form of a spiral (see Figure 5).

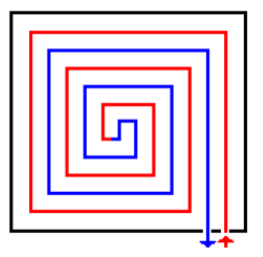

Fig. 5. Typical installation method for underfloor heating [3]
For the variant study, the pipes are installed individually in a string without loops. To investigate the flaw between the detailed pipe model and the simplified pipe model, 3 simulations have been set up. For the realistic model, two pipes are created from one pipe, each is half of the initial pipe length. Then the flux temperature of pipe $\mathrm{B}$ is iteratively determined with the return temperature of pipe A and used after convergence is achieved. Now the results of the temperatures and heat fluxes can be evaluated.

Only Delphin - simplified model - is compared to Delphin - detailed model. The deviation between the results of the two models is about $5 \%$. This was tested using 3 selected simulations. All result comparisons were showing a similar tendency. Therefore, the undivided pipe model (simplified model) was used for all further considerations.

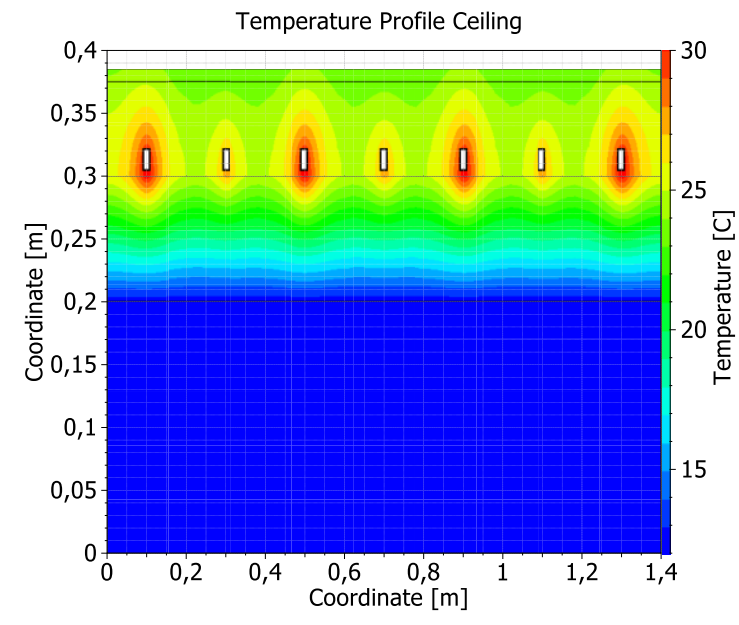

Fig. 6. Temperature profile detailed model

\section{Model Description}

\subsection{Pipe heat loss}

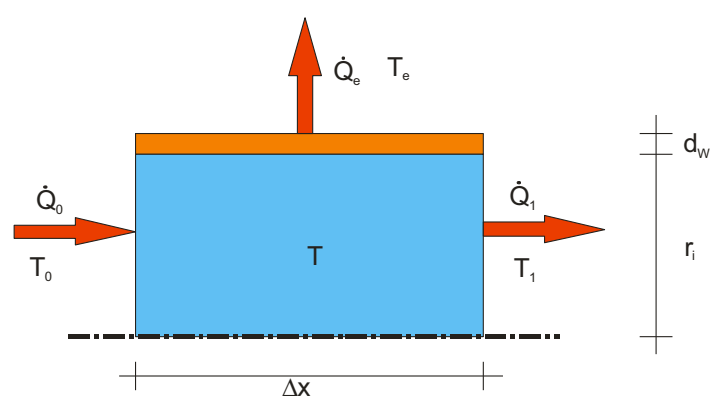

Fig. 7. Pipe model

The heat fluxes of the flowed-through pipe are described by the following equations:

$$
\begin{gathered}
\dot{Q}_{i}=\dot{m} \cdot c \cdot T_{i} \\
i=1 \ldots 2
\end{gathered}
$$




$$
\dot{Q}_{e}=U_{R} \cdot \Delta x \cdot\left(T_{1}-T_{e}\right)
$$

With length-related heat transfer coefficient for the pipe wall $\mathrm{U}_{\mathrm{R}}$ :

$$
\begin{gathered}
U_{R}=\frac{2 \cdot \pi}{\sum_{j=1}^{N} \frac{D_{j}}{\lambda_{j}}+\frac{1}{r_{i} \cdot h_{i}}+\frac{1}{r_{e} \cdot h_{e}}} \\
D_{j}=\ln \left(1+\frac{d_{j}}{r_{i}+\sum_{k=1}^{j-1} d_{k}}\right)=\ln \left(\frac{r_{j}}{r_{j-1}}\right) \\
r_{e}=r_{i}+\sum_{j=1}^{N} d_{j} \\
r_{j}=r_{i}+\sum_{k=1}^{j} d_{k}
\end{gathered}
$$

Subsequently the heat balances are calculated:

$$
\dot{Q}_{0}=\dot{Q}_{1}+\dot{Q}_{e}
$$

After conversion the following integral results:

$$
\int_{T_{0}}^{T} \frac{1}{T-T_{e}} d T=-\frac{U_{R}}{\dot{m} \cdot c} \cdot \int_{0}^{x} d x
$$

The following principles are required for the conversion:

$$
\begin{gathered}
T_{1}-T_{0}=\Delta T \\
T=T_{1}
\end{gathered}
$$

This is converted to $T(x)$ as follows. This describes the temperature at point $\mathrm{x}$ of the pipe:

$$
T(x)=e^{-\frac{U_{R}}{\dot{m} \cdot c} \cdot x} \cdot\left(T-T_{e}\right)+T_{e}
$$

After inserting $\mathrm{T}(\mathrm{x})$ into the heat flux $\mathrm{Q}_{\mathrm{e}}$, a location dependence for the heat flux can also be described.

$$
\dot{Q}_{e}(x)=U_{R} \cdot \Delta x \cdot\left(e^{-\frac{U_{R}}{\dot{m} \cdot c} \cdot x} \cdot\left(T_{0}-T_{e}\right)\right)
$$

After integration there is a heat loss/gain for the pipe with the length $\mathrm{L}$ :

$$
\dot{Q}_{e}=\dot{m} \cdot c \cdot\left(T_{0}-T_{e}\right) \cdot\left(1-e^{-\frac{U_{R}}{\dot{m} \cdot c} L}\right)
$$

$$
h=\frac{N u \cdot \lambda}{d_{\text {iPipe }}}
$$

In fluid mechanics there are three different flow ranges: laminar, turbulent and a transition range. The classification of the ranges is mainly based on the Reynolds number.

$$
R e=\frac{\rho \cdot v \cdot d}{\eta}
$$

Laminar $\operatorname{Re} \leq 2300$, turbulent $\operatorname{Re}>10000$ und transition range $2300<\operatorname{Re} \leq 10000$.[8]

Since the material properties are temperature-dependent, they can also fluctuate. This fluctuation is disregarded for the low-temperature systems with which underfloor heating systems are operated. For two different temperatures usually found in the building industry, the Reynolds numbers, the Nusselt numbers and the heat transfer coefficients are shown in Table 3.

\section{Constant Assumptions:}

Velocity $0.3 \mathrm{~m} / \mathrm{s}$

Diameter(internal) $8 \mathrm{~mm}$

Table 3. Coefficients in relation to fluid temperature

\begin{tabular}{|l|c|c|}
\hline & $20^{\circ} \mathrm{C}$ & $40^{\circ} \mathrm{C}$ \\
\hline Density in $\mathrm{kg} / \mathrm{m}^{3}[6]$ & 998,21 & 992,22 \\
\hline Viscosity in $10^{-3} \mathrm{~Pa} \cdot \mathrm{s}[6]$ & 1.0016 & 0.6530 \\
\hline Reynolds Number & 2392 & 3647 \\
\hline Nusselt Number & 15 & 26 \\
\hline $\begin{array}{l}\text { Heat Transfer Coefficient } \\
\text { in W/m }\end{array}{ }^{2} \mathrm{~K}$ & 1144 & 1978 \\
\hline
\end{tabular}

For heat transfer coefficients this high (table 2), the feedback effect on the heat flux is very low, because the resistance is considered $1 / h_{c}$. Therefore, heat flux reductions are practically non-existent.

The formula data sets are shown as follows:

$$
\operatorname{Pr}=\frac{\eta \cdot c}{\lambda}
$$

With the pressure loss coefficient for technically rough pipes by Konakov [4].

$$
\xi=\frac{1}{(1.82 \cdot \log R e-1.64)^{2}}
$$

The Nusselt number is defined separately for the three ranges. [1]

$$
N u_{\text {laminar }}=3.66
$$




$$
\begin{aligned}
& N u_{\text {turbulent }} \\
& =\frac{\frac{\xi}{8} \cdot \operatorname{Re} \cdot \operatorname{Pr}}{1+12.7 \cdot \sqrt{\frac{\xi}{8}} \cdot\left(\operatorname{Pr}^{2 / 3}-1\right)} \\
& \cdot\left(1+\left(\frac{d}{L}\right)^{2 / 3}\right) \\
& N u_{\text {transition }}=(1-\gamma) \cdot N u_{\text {laminar }}+\gamma \\
& \text { - Nu } u_{\text {turbulent }} \\
& \gamma=\frac{R e-2300}{10000-2300}
\end{aligned}
$$

Definition of the symbols

$\rho$ Density in $\mathrm{kg} / \mathrm{m}^{3}$

$\lambda$ Thermal conductivityin $\mathrm{W} /(\mathrm{mK})$

$\eta$ dynamic viscosity in $\mathrm{Pa} \cdot \mathrm{s}$

c Storage capacity in $\mathrm{J} /(\mathrm{kgK})$

$\mathrm{d}$ Pipe diameter(internal) in $\mathrm{m}$

$\mathrm{L}$ Pipe length in $\mathrm{m}$

\section{Implementation}

\subsection{Delphin}

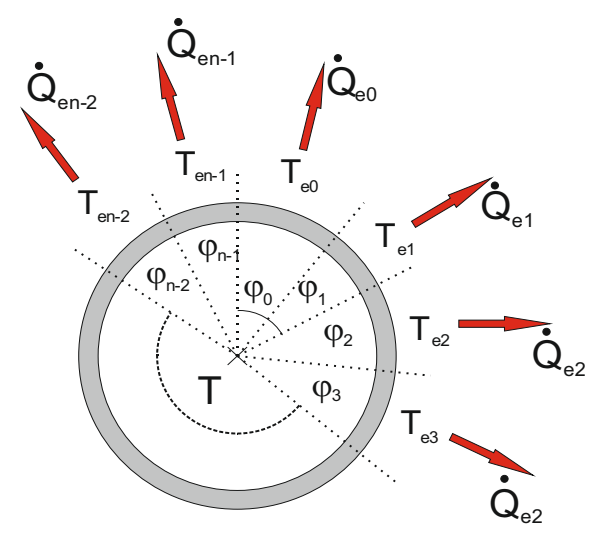

Fig. 8. Pipe model Delphin

In Delphin there is a separate model for the pipe model. The model determines the heat flux over the pipe shell according to the above equations. This is assigned to a boundary condition afterwards. The length of the boundary condition elements should be equivalent to the pipe diameter in order to achieve good results for the overall model. The heat flux itself is independent of length and is always distributed over the length of the boundary condition elements. If the lengths are too small, this can lead to a temperature increase that does not exist in reality. If the length is too large, the temperatures are too low. Figure 8 shows the temperature distribution over the tube wall and figure 9 pictures the subsequent mapping to a rectangular body. The calculation formulas will not be discussed further.

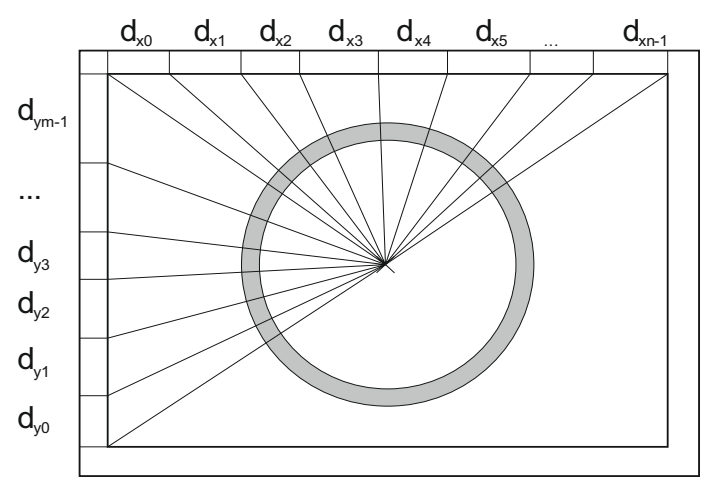

Fig. 9. Rectangular body pipe model Delphin

\subsection{Delphin}

In NANDRAD the heat flux is also calculated according to the above equations. As there is no $2 \mathrm{D}$ or $3 \mathrm{D}$ discretization like in Delphin but only a 1D discretization, the heat flux must be distributed over a component surface. This does not result in temperature differences like in Delphin. The temperature waves on the surface are missing and there is only an average temperature instead. For a building simulation solver, this is acceptable. In this case, it is important that the heat fluxes of the simple and the detailed model are as similar as possible.

\section{Comparison}

\subsection{D Comparison}

In the one-dimensional case the results of NANDRAD and Delphin show exact correlation. For the case described, differences can only be shown in the decimal places.

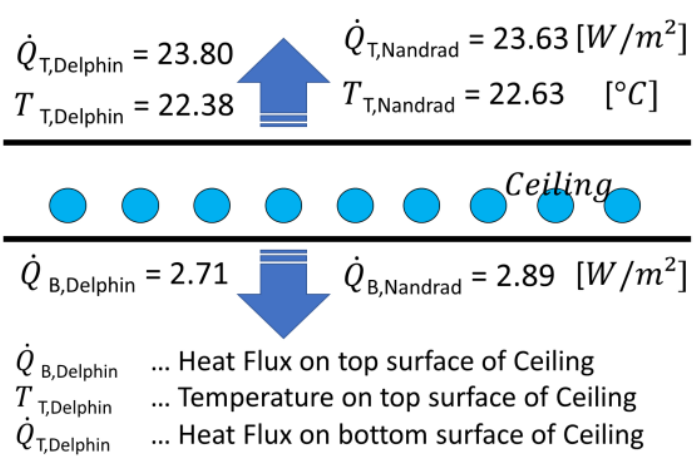

Fig. 10. Results 1D Comparison

\subsection{D Comparison}

The results are approximately consistent for small installation distances no matter which flux temperature, installation condition or inner diameter are chosen. With larger installation distances, the results diverge, also independent of the other variation parameters. This can be recognized in figure 11 and figure 12. 


\begin{tabular}{|c|c|c|c|c|}
\hline \multicolumn{5}{|c|}{ Upper Surface Temperature Deviations Ceiling in ${ }^{\circ} \mathrm{C}$} \\
\hline \multirow{3}{*}{\multicolumn{2}{|c|}{$\begin{array}{l}\text { Inlet temperature } \\
\text { Boundary condition }\end{array}$}} & 25 & \multicolumn{2}{|c|}{${ }^{\circ} \mathrm{C}$} \\
\hline & & Storey & \\
\hline & & 1 & $\mathrm{~m} / \mathrm{s}$ & \\
\hline \multirow{2}{*}{\multicolumn{2}{|c|}{ Velocity }} & \multicolumn{3}{|c|}{ Installation distance in $\mathrm{mm}$} \\
\hline & & 50 & 100 & 200 \\
\hline \multirow{4}{*}{ 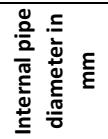 } & 8 & $-0.2^{\circ} \mathrm{C}$ & $-0.1^{\circ} \mathrm{C}$ & $-0.3^{\circ} \mathrm{C}$ \\
\hline & 10 & $0.0^{\circ} \mathrm{C}$ & $-0.1^{\circ} \mathrm{C}$ & $-0.4^{\circ} \mathrm{C}$ \\
\hline & 12 & $0.1^{\circ} \mathrm{C}$ & $-0.1^{\circ} \mathrm{C}$ & $-0.5^{\circ} \mathrm{C}$ \\
\hline & 16 & $-0.1^{\circ} \mathrm{C}$ & $-0.1^{\circ} \mathrm{C}$ & $-0.6^{\circ} \mathrm{C}$ \\
\hline
\end{tabular}

Fig. 11. Results deviations 2D comparison (1)

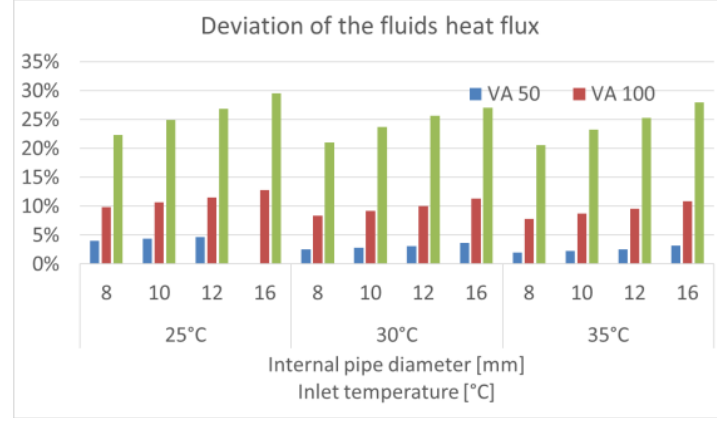

Fig. 12. Results deviations for boundary condition "storey"

\begin{tabular}{|c|c|c|c|c|}
\hline \multicolumn{5}{|c|}{ Upper Surface Temperature Ceiling in ${ }^{\circ} \mathrm{C}$} \\
\hline \multirow{2}{*}{\multicolumn{2}{|c|}{$\begin{array}{l}\text { Inlet temperature } \\
\text { Boundary condition }\end{array}$}} & 35 & \multicolumn{2}{|l|}{${ }^{\circ} \mathrm{C}$} \\
\hline & & Storey & & \\
\hline \multicolumn{2}{|c|}{ Velocity } & 1 & \multicolumn{2}{|l|}{$\mathrm{m} / \mathrm{s}$} \\
\hline & & \multicolumn{3}{|c|}{ Installation distance in $\mathrm{mm}$} \\
\hline & & 50 & 100 & 200 \\
\hline \multirow{4}{*}{ 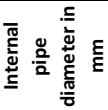 } & 8 & 27.4 & 26.5 & 25.3 \\
\hline & 10 & 27.8 & 27.1 & 26.1 \\
\hline & 12 & 28.0 & 27.5 & 26.6 \\
\hline & 16 & 28.2 & 27.9 & 27.3 \\
\hline
\end{tabular}

\begin{tabular}{|c|c|c|c|c|}
\hline \multicolumn{5}{|c|}{ Upper Surface Heat Flux Ceiling $\mathrm{W} / \mathrm{m}^{2}$} \\
\hline \multirow{2}{*}{\multicolumn{2}{|c|}{$\begin{array}{l}\text { Inlet temperature } \\
\text { Boundary condition }\end{array}$}} & 35 & \multicolumn{2}{|c|}{ c } \\
\hline & & Storey & \\
\hline \multirow{3}{*}{\multicolumn{2}{|c|}{ Velocity }} & 1 & & \\
\hline & & \multicolumn{3}{|c|}{ Installation distance in $\mathrm{mm}$} \\
\hline & & 50 & 100 & 200 \\
\hline \multirow{4}{*}{ 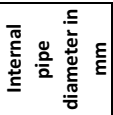 } & 8 & 75.8 & 66.6 & 53.6 \\
\hline & 10 & 79.5 & 72.5 & 61.7 \\
\hline & 12 & 81.5 & 76.0 & 66.8 \\
\hline & 16 & 83.7 & 79.8 & 73.0 \\
\hline
\end{tabular}

\begin{tabular}{|c|c|c|c|c|}
\hline \multicolumn{5}{|c|}{ Heat Flux Pipe in W/m² } \\
\hline \multirow{5}{*}{\multicolumn{2}{|c|}{$\begin{array}{l}\text { Inlet temperature } \\
\text { Boundary condition } \\
\text { Velocity }\end{array}$}} & 35 & \\
\hline & & Storey & & \\
\hline & & 1 & & \\
\hline & & \multicolumn{3}{|c|}{ Installation distance in $\mathrm{mm}$} \\
\hline & & 50 & 100 & 200 \\
\hline \multirow{4}{*}{ 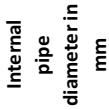 } & 8 & 84.8 & 74.5 & 60.0 \\
\hline & 10 & 88.9 & 81.1 & 69.0 \\
\hline & 12 & 91.2 & 85.0 & 74.8 \\
\hline & 16 & 93.6 & 89.2 & 81.6 \\
\hline
\end{tabular}

\begin{tabular}{|c|c|c|c|c|}
\hline \multicolumn{5}{|c|}{ Outlet Temperature in ${ }^{\circ} \mathrm{C}$} \\
\hline \multirow{2}{*}{\multicolumn{2}{|c|}{$\begin{array}{l}\text { Inlet temperature } \\
\text { Boundary condition }\end{array}$}} & 35 & \\
\hline & & Storey & & \\
\hline \multirow{3}{*}{\multicolumn{2}{|c|}{ Velocity }} & 1 & & \\
\hline & & \multicolumn{3}{|c|}{ Installation distance in $\mathrm{mm}$} \\
\hline & & 50 & 100 & 200 \\
\hline \multirow{4}{*}{ 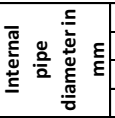 } & 8 & 33.0 & 31.5 & 29.3 \\
\hline & 10 & 33.7 & 32.6 & 30.8 \\
\hline & 12 & 34.0 & 33.2 & 31.8 \\
\hline & 16 & 34.4 & 33.9 & 33.1 \\
\hline
\end{tabular}

Fig. 13. NANDRAD Results for boundary condition "storey"
Figure 13 and Figure 15 show the results of the surface temperatures and the heat flux of the upper side of the floor/ceiling component as well as the heat flux of the pipe and the outlet temperature of the fluid for the simulations in NANDRAD and Delphin of the variant inlet temperature $35^{\circ} \mathrm{C}$ and boundary condition "storey".

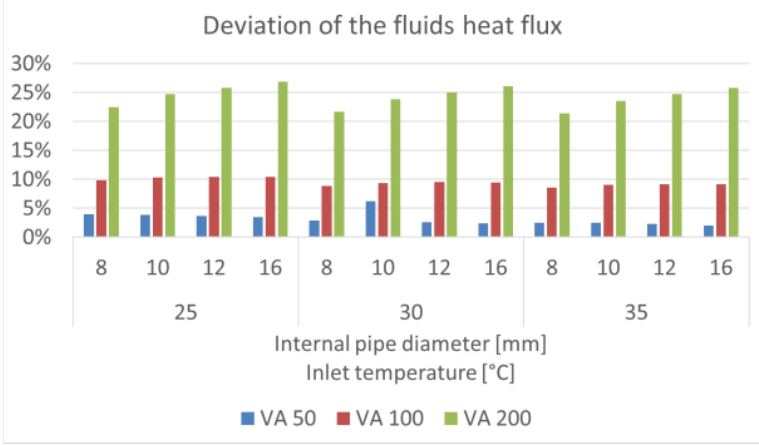

Fig. 14. Results deviations for boundary condition "ground"

\begin{tabular}{|c|c|c|c|c|}
\hline \multicolumn{5}{|c|}{ Upper Surface Temperature Ceiling in ${ }^{\circ} \mathrm{C}$} \\
\hline \multirow{3}{*}{\multicolumn{2}{|c|}{$\begin{array}{c}\text { Inlet temperature } \\
\text { Boundary condition } \\
\text { Velocity }\end{array}$}} & $=35$ & \multirow{2}{*}{\multicolumn{2}{|c|}{${ }^{\circ} \mathrm{C}$}} \\
\hline & & Storey & & \\
\hline & & 1 & \multicolumn{2}{|l|}{$\mathrm{m} / \mathrm{s}$} \\
\hline & & \multicolumn{3}{|c|}{ Installation distance in $\mathrm{mm}$} \\
\hline & & 50 & 100 & 200 \\
\hline \multirow{4}{*}{ 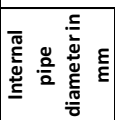 } & 8 & 27.4 & 26.1 & 24.2 \\
\hline & 10 & 27.8 & 26.6 & 24.7 \\
\hline & 12 & 28.0 & 26.9 & 25.0 \\
\hline & 16 & 28.2 & 27.3 & 25.4 \\
\hline
\end{tabular}

\begin{tabular}{|c|c|c|c|c|}
\hline \multicolumn{5}{|c|}{ Upper Surface Heat Flux Ceiling $\mathrm{W} / \mathrm{m}^{2}$} \\
\hline \multirow{3}{*}{\multicolumn{2}{|c|}{$\begin{array}{c}\text { Inlet temperature } \\
\text { Boundary condition } \\
\text { Velocity }\end{array}$}} & 35 & \multirow{2}{*}{\multicolumn{2}{|c|}{${ }^{\circ} \mathrm{C}$}} \\
\hline & & Storey & & \\
\hline & & 1 & \\
\hline & & \multicolumn{3}{|c|}{ Installation distance in $\mathrm{mm}$} \\
\hline & & 50 & 100 & 200 \\
\hline \multirow{4}{*}{ 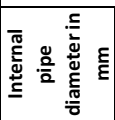 } & 8 & 74.0 & 61.0 & 42.1 \\
\hline & 10 & 77.7 & 66.0 & 47.1 \\
\hline & 12 & 79.8 & 69.0 & 50.2 \\
\hline & 16 & 82.2 & 72.5 & 54.0 \\
\hline
\end{tabular}

\begin{tabular}{|c|c|c|c|c|}
\hline \multicolumn{5}{|c|}{ Heat Flux Pipe in W/m² } \\
\hline \multirow{2}{*}{\multicolumn{2}{|c|}{$\begin{array}{l}\text { Inlet temperature } \\
\text { Boundary condition }\end{array}$}} & 35 & \multicolumn{2}{|c|}{ c } \\
\hline & & Storey & \\
\hline \multirow{3}{*}{\multicolumn{2}{|c|}{ Velocity }} & 1 & & \\
\hline & & \multicolumn{3}{|c|}{ Installation distance in $\mathrm{mm}$} \\
\hline & & 50 & 100 & 200 \\
\hline \multirow{4}{*}{ 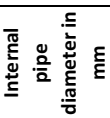 } & 8 & 82.5 & 67.9 & 46.9 \\
\hline & 10 & 86.5 & 73.5 & 52.4 \\
\hline & 12 & 88.8 & 76.9 & 55.9 \\
\hline & 16 & 91.4 & 80.7 & 60.1 \\
\hline
\end{tabular}

\begin{tabular}{|c|c|c|c|c|}
\hline \multicolumn{5}{|c|}{ Outlet Temperature in ${ }^{\circ} \mathrm{C}$} \\
\hline \multirow{2}{*}{\multicolumn{2}{|c|}{$\begin{array}{l}\text { Inlet temperature } \\
\text { Boundary condition }\end{array}$}} & 35 & \multicolumn{2}{|c|}{${ }^{\circ} \mathrm{C}$} \\
\hline & & Storey & \\
\hline \multicolumn{2}{|c|}{ Velocity } & 1 & & \\
\hline & & \multicolumn{3}{|c|}{ Installation distance in $\mathrm{mm}$} \\
\hline & & 50 & 100 & 200 \\
\hline \multirow{4}{*}{ 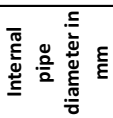 } & 8 & 33.0 & 31.8 & 30.5 \\
\hline & 10 & 33.7 & 32.8 & 31.8 \\
\hline & 12 & 34.1 & 33.4 & 32.6 \\
\hline & 16 & 34.5 & 34.0 & 33.6 \\
\hline
\end{tabular}

Fig. 15. DELPHIN Results for boundary condition "storey"

Figure 14 shows that for an increasing pipe diameter, but especially for an increasing installation distance, the deviations between the results of the models are increasing as well. Absolute deviations between 
NANDRAD and Delphin can be determined from figure 13 and figure 15. The deviations for smaller installation distances $(<200 \mathrm{~mm})$ are considered acceptable from an engineering perspective and the simplified model can be used here.

In order to investigate the influence of the fluids mass flux, the results with a fluid velocity of $1 \mathrm{~m} / \mathrm{s}$, which is in the turbulent range, were compared to a laminar flow variant with a fluid velocity of $0.1 \mathrm{~m} / \mathrm{s}$. Again, the simplified model in NANDRAD is compared to the detailed model of Delphin. Figure 15 shows the deviations of both variants.

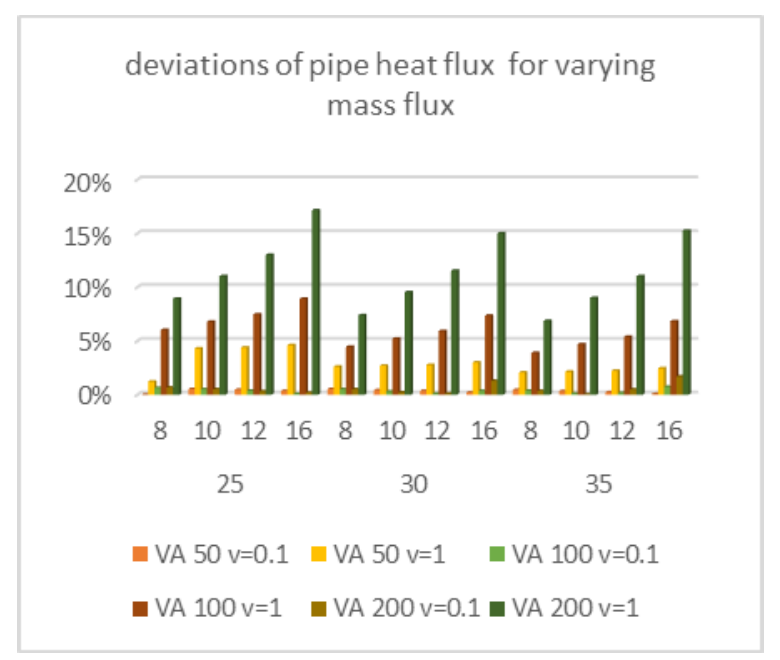

Fig. 16. Deviations for various mass fluxes

It becomes obvious that with decreasing velocity of the fluid and therefore lower mass flux as well, the deviation between the models is also reduced. Since the flow velocity in underfloor heating systems is at a maximum of $1 \mathrm{~m} / \mathrm{s}$, a kind of worst case was examined here and the results (Figure 13,15 ) represent a highly conservative scenario.

\section{Conclusion}

The pipe model can easily be used up to an installation distance of $100 \mathrm{~mm}$. Here the deviations of the pipe heat flux remain below $15 \%$. In this case, a poorly conducting screed was specifically selected for reducing the crossconduction of the heat. The better the thermal conductivity of the material in which the pipes are embedded, the better the distribution of the heat within the layer and the model deviations become smaller. Furthermore, the maximum possible flow velocity was applied. The higher the flow velocity, the greater the deviations. At lower flow velocities even larger installation distances can be adequately simulated. Therefore, the variants shown above are representing a rather conservative case.

Consequently, NANDRAD can be used for the analysis of surface heating systems under the restrictions mentioned above, since the results of the NANDRAD calculation are reasonably similar to the results of detailed models of professional software (Delphin).

\section{References}

[1] VDI Gesellschaft Verfahrenstechnik. (2005). VDIWärmeatlas 10. Aufl. 2006. Wiesbaden: Springer Berlin Heidelberg.

[2] Delphin. (17.01 2020). Von http://bauklimatikdresden.de/delphin/index.php abgerufen

[3] Hirth, S. (2019). Diplomarbeit: Validierung der Heizungsverteilung der Software BIM HVACTool mit dem Gebäudesimulationssolver NANDRAD. Dresden.

[4] Konakov, T. (kein Datum). Eine neue Formel für den Reibungskoeffizienten glatter Rohre. Bericht der Akademie der Wissenschaften der UDSSR Vol. 51, S. 503-506.

[5] NANDRAD. (17.01 2020). Von http://bauklimatik-dresden.de/nandrad/index.php abgerufen

[6] NIST. (17.01 2020). Von https://webbook.nist.gov/cgi/fluid.cgi? $\mathrm{P}=1 \&$ TLow $=20 \&$ THigh $=40 \&$ TInc $=1 \&$ Applet $=$ on $\&$ Digits $=5 \&$ ID $=\mathrm{C} 77321$ 85\&Action $=$ Load\&Type $=$ IsoBar\&TUnit $=$ C\&PUnit $=$ bar $\&$ DUnit $=\mathrm{kg} \% 2 \mathrm{Fm} 3 \&$ HUnit $=\mathrm{kJ} \% 2 \mathrm{Fmol} \& \mathrm{WUnit}=\mathrm{m} \% 2 \mathrm{~F}$ $\mathrm{s} \& \mathrm{~V}$ isUnit $=\mathrm{Pa} * \mathrm{~s} \& \mathrm{STUnit}=\mathrm{N} \% 2 \mathrm{Fm} \&$ RefState $=\mathrm{DEF}$ abgerufen

[7] Qucosa. (17.01 2020). Von https://nbnresolving.org/urn:nbn:de:bsz:14-qucosa-230427 abgerufen

[8] schweizer-fn. (17.01 2020). Von https://www.schweizer-fn.de/ abgerufen 